\title{
PIGLIA EN ONETTI
}

REFLEXIONES SOBRE LA ESTRUCTURA DE PARA UNA TUMBA SIN NOMBRE

\section{Gabriella Zombory}

Universidad Eötvös Loránd de Budapest

zgabi.ar@gmail.com

Resumen: Aproximándose a la novela breve Para una tumba sin nombre de Juan Carlos Onetti a través del modelo estructural para la nouvelle propuesto por Ricardo Piglia, con el objetivo de examinar su aplicabilidad en el análisis de la obra, se pueden descubrir en ella dos niveles de lectura bien diferenciables pero interrelacionados. Serán justo las incongruencias frente al modelo pigliano en el primer nivel las que indican la posibilidad de una segunda lectura, contribuyendo dicho modelo, por lo tanto, al desciframiento estructural de la novela breve analizada, revelando en ella un sistema de reduplicaciones o, quizás aún, multiplicaciones infinitas.

Palabras clave: nouvelle, el misterio de contar historias, estructura múltiple, Ricardo Piglia, Juan Carlos Onetti

\section{PIGLIA IN ONETTI}

REFLECTIONS ON THE STRUCTURE OF PARA UNA TUMBA SIN NOMBRE

\begin{abstract}
By approaching Juan Carlos Onetti's short novel Para una tumba sin nombre through the structural model proposed for nouvelle by Ricardo Piglia, in order to examine its applicability in the analysis of the work, one can discover two clearly different, but interrelated levels of reading. It will be precisely the inconsistencies with the Piglian model in the first level what leads to discover the possibility of a second reading, thus contributing said model to decipher the structure of the here analysed short novel, revealing a system of reduplications, or maybe even infinite multiplications.
\end{abstract}

Keywords: nouvelle, the mystery of storytelling, multiple structure, Ricardo Piglia, Juan Carlos Onetti

DOI: $\underline{\text { https://doi.org/10.24029/lejana.2020.13.434 }}$

Recibido: el 24 de noviembre de 2018

Aceptado: el 1 de marzo de 2019

Publicado: el 19 de febrero de 2020 
Observando los tomos que reúnen gran parte de la narrativa breve de Juan Carlos Onetti, inmediatamente se notará que entre los títulos que comprenden Novelas breves (2012) y Cuentos completos (2014), varios, entre ellos "La cara de la desgracia", "Jacob y el otro", "La muerte y la niña", etc., se repiten en ambas recopilaciones, fenómeno que, sin duda, será propio de la obra de otros tantos autores de narrativa breve. A falta de una definición genérica clara entre cuento y novela breve, tal como lo ha reconocido Mario Benedetti ya en 1953, se ha establecido la costumbre de "ordenar las obras narrativas [...] teniendo en cuenta para ello sólo la extensión" (1968: en línea), aproximación que ya ab ovo conlleva una serie de inconvenientes. La cuantía de los folios varía en cada teorización; mientras que, por ejemplo, Benedetti define el cuento en un máximo de veinte páginas, y la novela breve, entre unos cincuenta y ciento veinte (1968: en línea), el escritor Eloy Tizón considera que este último género se sitúa entre ochenta y cien páginas; ${ }^{1}$ sin que ninguno de ellos especificara el tamaño del papel, la fuente y tamaño de letra, el interlineado, etc. Y como ya se nota de las especificaciones anteriores, este tipo de ordenación meramente por número de páginas, naturalmente, significaría que algunas obras se queden en una zona fronteriza en cuanto a su extensión, dificultando su inclusión en una u otra categoría. Frente a esta situación insuficiente y algo confusa, Ricardo Piglia, en sus tres ensayos "Tesis sobre el cuento" (1986), "Nuevas tesis sobre el cuento" (1999) y "Secreto y narración. Tesis sobre la nouvelle" (2005), ha propuesto una posible aclaración en cuanto a los límites entre los dos géneros en cuestión. Dejando a un lado una distinción meramente de cantidad, o una definición basada en la cantidad y el tipo de información proporcionada al lector (tal como lo hace Benedetti en 1953), ${ }^{2}$ Piglia establece un modelo estructural, señala técnicas narrativas que denota como propias de cada uno de los dos géneros, y junto con algunas afirmaciones categóricas, enumera varios motivos que ve quizás no como constantes fijas, pero sí como recurrentes en la formación de una nouvelle: de esta manera, llegaría a racionalizar hasta cierto punto el trabajo crítico sobre los textos. Su argumentación, no obstante, aunque sugerente, ya a primera vista parece poco fundamentada, al justificar toda una teoría de la novela breve mediante el análisis de una única obra: Los adioses de Juan Carlos Onetti. Aunque de paso sí menciona a varios otros autores, entre ellos a Henry James, a Conrad, a Rulfo o a Fuentes, demuestra sus teorías detenidamente solo en la obra mencionada del autor uruguayo.

Por consiguiente, con el objetivo de comprobar la vigencia (o lo contrario) de las tesis sobre la nouvelle propuestas por Piglia, y ampliar el marco de su fundamentación, en este trabajo intentaré confirmar si sus ideas son aplicables al menos a otras obras del mismo autor, utilizando el método del crítico argentino sobre otro de los textos breves de Onetti del que,

\footnotetext{
${ }^{1}$ Sugerido en su ponencia "Libro de voces. Una lectura personal de la novela breve" leída en la conferencia $L a$ novela corta moderna en el mundo hispánico. XI Coloquio Internacional de Estudios Hispánicos, Budapest: Universidad Eötvös Loránd / Centro de Investigaciones sobre América Latina, 24 de octubre de 2018.

${ }^{2}$ Benedetti denota tanto el cuento como la nouvelle como un "corte transversal efectuado en la realidad", con la distinción de que mientras el cuento presenta algo instantáneo y al final sorprende, asombra a su lector con la revelación, la nouvelle muestra proceso y evolución, rodea su trozo de vida de pormenores, antecedentes o consecuencias según lo vea conveniente; en vez de sorprender, explica, y excita la curiosidad o la sensibilidad del lector de manera progresiva (1968: en línea). En ningún momento quiero decir que la distinción de Benedetti carezca de fundamento; deseo señalar nomás que él designa solo la clase de contenido que se debe incluir en cada género y el efecto que se debe causar en el lector, pero no llega a aclarar los procedimientos para llegar a tal efecto.
} 
según la crítica, no cabe duda de ser identificado como novela breve, por lo cual, deberían reconocerse en ella con facilidad al menos las observaciones más categóricas de Piglia.

Para una tumba sin nombre (1959) ya a primera vista se adecua al modelo pigliano, reuniendo en sí un gran número de características que el argentino subraya: 1) Como núcleo de su funcionamiento, tras la novela breve late un secreto (Piglia, 2006: 200), en concreto, el misterio de la cabra acompañando el precario cortejo fúnebre de una mujer de identidad dudosa. 2) Sobre dicho secreto, punto de partida de la narración, el narrador obtiene una "percepción parcial", a partir de la cual intentará investigar, entender el resto de la historia que le corresponde al elemento visto (2006: 196-197): es decir, el médico, Díaz Grey, por casualidad se entera del entierro encargado por Jorge Malabia, decide asistir, y allí, ve al cabrón misterioso caminando junto al joven; a partir de dicha escena, el médico intenta reconstruir la prehistoria de Jorge, la cabra y la mujer. 3) De esta manera, en narrador principal está contando "una historia que no es la de él, se interesa por una historia que le es ajena”, en la que no participa — en realidad al médico no le afecta la vida ni de Jorge, ni de Rita, ni de la cabra—, y solo narra por curiosidad, por querer entender (2006: 196). Por esta misma razón estamos frente a un narrador incierto que "trata de avanzar en la historia a ver si puede descifrar lo que está pasando" (2006: 195). Mediante los testimonios de Jorge y Tito van sabiéndose poco a poco diferentes vertientes (o diferentes versiones) de lo ocurrido, y va formándose cada vez más la imagen. 4) Estos testimonios siempre ocurren en forma de conversaciones personales y, además, la escena que Jorge le cuenta primero al médico es una historia que escuchó contar en un bar, con lo cual todo el texto "mantiene el marco [...] del relato oral", y en ello, el motivo de la circulación de las historias (2006: 201). 5) Sin embargo, a pesar de todo trabajo de investigación del narrador, el secreto planteado, esto es, el misterio de la cabra, "nunca [se] descifra por completo" (2006: 194), dejando abierto el desenlace de la obra, por lo cual, el final del texto escrito "no coincide [...] con el final mismo de la historia" (2006: 204), manteniendo lo narrado en un suspense continuo, en una ambigüedad eterna. 6) El secreto así siempre irresuelto, "lugar vacío" de la narración, sirve como motivo de la investigación y, así, de la narración misma, y en especial, como motivo para unir las varias tramas contadas a lo largo de la obra (2006: 200): Para una tumba sin nombre se compone de una multitud de sub-historias surgidas durante el proceso de investigación del médico; entre ellas encontramos la historia del entierro supuestamente visto, las escenas de Tito y Jorge en Buenos Aires en dos versiones (una vez narrada por Jorge y otra, por Tito), la prehistoria de Rita y Ambrosio sobre el "nacimiento" de la cabra, la escena de Rita y la cabra en la estación (contada inicialmente por Godoy), etc. Y todas ellas encuentran su razón de ser en la narración de Díaz Grey por ser diferentes aproximaciones al mismo misterio a descifrar: al significado real de la cabra. Por medio del proceso de investigación sobre el secreto irresuelto de la cabra, entonces, se logra "concentrar historias múltiples", se logra justificar haber contado el mismo cuento muchas veces (2006: 201).

Claro es, varias de estas características no son exclusivas de la novela breve; aún Piglia expresa que algunos de ellos son requisitos tanto del cuento como de la nouvelle, siendo exclusivos solo el no-desciframiento del secreto, el no-coincidir el final del texto con el de la historia, y la estructura de contar un cuento múltiples veces, anudándose sobre un punto oscuro (2006: 194, 204, 201). Con todo, Para una tumba sin nombre sí reuniría un gran 
número de los motivos señalados por Piglia como propios o recurrentes de una nouvelle, siendo así un modelo ejemplar para probar la validez de sus tesis.

Demos, no obstante, un paso más, y profundicemos un poco en el análisis de la obra: tras matizar las afirmaciones antes establecidas, se verá que varias de ellas pueden socavarse hasta cierto punto. La existencia del secreto de la cabra como punto de partida persiste; es, sin duda, la escena de la cabra en el entierro, supuestamente vista por el narrador principal en persona, la que crea la necesidad de narrar. Sin embargo, en ningún momento existe una intención en el médico de comenzar una investigación real, de "entrar en la casa" después de haber visto una escena por su ventana, tal como ejemplifica el proceso el mismo Piglia (2006: 196-197). Tras haber presenciado el entierro, es el mismo joven Malabia quien le reprocha esta actitud inactiva frente a lo insólito: “¿Por qué no me hace preguntas?” (Onetti, 2012: 125); "Pero usted, ¿por qué no pregunta? La pata del cabrón no le interesa. Pregunte por la mujer, por la muerta. Si era mi amante, si nos casamos en secreto, si era mi hermana emputecida" (2012: 126). Aun teniendo al testigo más adecuado enfrente, Díaz Grey no muestra interés alguno por revelar la verdad y narrarla. Es luego, también por iniciativa propia de Jorge que este visita al médico para hablarle sobre el caso ("Se lo debía y vine" [2012: 128]); es el joven el que siente una necesidad, una obligación hacia el médico de contarle su parte de la historia de Rita y la cabra. Más adelante, como el narrador mismo lo confiesa sobre el testimonio recibido de Tito, "[e]1 segundo encuentro fue también casual” (2012: 169): una tarde el médico lo reconoce en un bar y, ya que el azar se lo ha puesto al lado, le dirige la palabra. Luego, al final de la nouvelle, al recibir por fin una prueba física sobre el caso - la carta de Tito-, el médico opta por no leerla y destruirla, prefiriendo ignorar la verdad. En cambio, decide dejar atrás la realidad real y construirse una realidad propia, ficticia, producto de su imaginación, tal como se nota con mayor fuerza en el capítulo III, en el que Díaz Grey toma la posición de un narrador extradiegético, y narra una prehistoria de la que, naturalmente, no ha podido ser testigo: "Bueno, me puse a adivinar cosas y las escribí", "Unas pocas páginas [...]. El insomnio, el aburrimiento y la incapacidad de participar en otra forma" (2012: 162). Pero esta versión inventada, que el médico crea confesadamente casi de la nada, queda luego aceptada como realidad tanto por Jorge como por Tito. "Las adivinó. Todo fue así" (2012: 163), dice el joven Malabia, con lo cual la existencia de Ambrosio, supuesto amante de Rita, se incorpora en la realidad, y esta ficción inventada llega a ser el elemento más fijo de todo el relato, ya que mediante las historias siempre cambiantes de Jorge y Tito, que se contradicen continuamente, la imagen real no se va completando, sino que se desestabiliza cada vez más: "las diferentes interpretaciones [...] van anulándose unas a otras" (Saer, 2012: 14), y en vez de luchar por alcanzar un desciframiento del enigma, más bien utilizan la estructura básica propuesta por Piglia para imposibilitar y ahogar la claridad.

Siguiendo las nociones piglianas, este desinterés del narrador principal hacia su narración lleva a pensar que en la novela, paralelamente a la primera, pueda haber un segundo núcleo secreto, algo por cuyo desciframiento el narrador o los narradores realmente trabajen. De mantener la cabra como el elemento secreto, el médico no sería tanto un narrador incierto en busca de la verdad, sino más bien un narrador desinteresado. Y este narrador desinteresado puede serlo por su capacidad de crear historias desde otra fuente que la referencial: por ser un narrador creador. Como tantos críticos lo han sostenido ya sobre la narrativa de Onetti en 
general, y sobre Para una tumba sin nombre en concreto, "el núcleo del cuento no es la fábula que cuenta" (Ferro, 2011: 322), sino el proceso de hacerlo. La nouvelle de Onetti, entonces, siendo este, junto con Macedonio Fernández, "el precursor solitario de [los] embates contra el sistema realista de la representación" (Saer, 2012: 16), no tiene intención alguna de entender la realidad de la cabra, sino, por lo contrario, desea enseñar que lo anterior no es necesario, que, desde un punto de partida real, un verdadero narrador tiene todas las herramientas para crear una realidad nueva y propia, que puede llegar a ser mucho más verdadera que la original. Volvamos entonces a ver si las tesis de Piglia se atienen también a esta segunda vertiente de la obra, en la que habrá que contar ya con Jorge en su posición de narrador secundario. 1) El secreto nuclear de la narración desde este punto de vista sería el misterio de contar historias. 2) Jorge Malabia, joven pretendiente a escritor (sabemos de él que ha escrito algunos poemas) se encuentra por casualidad con el médico, escritor de cuentos, perteneciente al grupo de "nosotros, los notables" (Onetti, 2012: 115), y además, un hombre con el que "es posible hablar" (2012: 160). Al encontrarse con una persona iniciada en el arte de narrar recibe un impulso, siente la necesidad de contar su historia, pero no sabe cómo; estando fuera del grupo del "nosotros" solo puede tener una visión parcial sobre los mecanismos de contar un cuento, por lo cual comienza su trabajo de investigación. Él sí acude a su testigo de manera voluntaria, visita o le dirige la palabra al médico en tres ocasiones para poder contarle (contándole en este caso la historia de la cabra, pero que en realidad podría ser cualquier otro relato diferente), y bajo la supervisión de este ir comprendiendo el secreto de la narración. "Puedo ayudarle" (2012: 124), se ofrece para ello Díaz Grey durante su primer encuentro, todavía casual. El médico, entonces, se presta al joven para dos funciones principales necesarias para su evolución como narrador, para su mayor entendimiento del arte de narrar: para escuchar sus repetidos intentos ("No necesito que me ayude de ninguna manera activa. Basta con que escuche. Pero solo si quiere" [2012, 142]), y para dirigirlo a lo largo de su trabajo, esto es, para proporcionarle información para un mejor entendimiento de cómo construir una narración ("Claro, de acuerdo. [...] ¿Tenían ventana hacia la calle? Si ella se instalaba al pie de la escalera de la plaza, ¿podían verla desde la ventana?” [2012: 139]; "Ahora estamos mucho mejor. [...] Ahora, el resto tiene que ser mucho más fácil. Se trata de unir esa escena con la del entierro, rellenar los ocho o nueve meses que las separan" [2012: 147]). ${ }^{4}$ El trabajo de entendimiento en este caso no es algo tan directo como el de una realidad oculta; se trata aquí de algo diferente: lo que Jorge debería entender para resolver el enigma ante él es que lo fundamental de la narración no es desmantelar un hecho real, sino crear a partir de él algo propio; no dejarse atar por lo real, sino experimentar con lo posible, y poder decir "Me llamo Jorge Malabia. No sucedió nada antes del día de mi nacimiento; y, si yo

\footnotetext{
${ }^{3}$ Las "reflexiones sobre el mundo y su representación, problema inherente a todo ejercicio del arte de narrar," en Onetti es elemento recurrente, dice Saer (2012: 15). Por su parte, Josefina Ludmer define Para una tumba sin nombre como "un texto vacío que solo cuenta y escribe que cuenta" (2009: 158), un texto que "exhibe al desnudo el molde de la narración que sostiene la mayoría de los relatos de Onetti" (2009: 178), siendo Onetti un escritor que "escribe, a escritores, sobre la escritura" (2009: 187). A la vez, Roberto Ferro también determina Para una tumba sin nombre como "escritura sobre la escritura" (2011: 309), un relato que "no tiene una esencia", ya que "la verdad que puede transmitir sólo es un proceso" (2011:317).

${ }^{4}$ Sobre el proceso de iniciación en la narración entre Jorge y el médico, véase Gabriella Zombory (2018): "Narración y rito de paso en Para una tumba sin nombre de Juan Carlos Onetti". En Zsuzsanna Bárkányi y Margit Santosné Blastik (eds.), Palabras enlazadas. Estudios en homenaje al profesor László Scholz. Szeged, JATEPress: 421-428.
} 
fuera mortal, nada podría suceder después de mí" (2012: 162). Luego, continuando con la observación de las tesis de Piglia sobre esta segunda lectura del texto, notaremos que, 3) durante su camino de aprendizaje, Malabia está investigando doblemente sobre un caso que no es el suyo. Primero, la historia de Rita es, principalmente, de Rita misma, y después de ella, de Godoy, primera persona que narró sobre ella. Y segundo, no olvidemos que el narrador principal de la obra sigue siendo el médico, es él quien finalmente cuenta la historia que nosotros, los lectores llegamos a leer, de manera que Jorge está intentando narrar un relato cuyo narrador real no es él. Por ello, y por no ser un narrador iniciado, Jorge tantea, esto es, es un narrador incierto: vuelve tres veces a ver al médico buscando nuevos caminos, e intenta descifrar su secreto. 4) El marco del relato oral aquí también persiste claramente, los únicos actos de escritura son el cuento del médico y la carta de Tito, colocándose cada narración de Jorge en el marco de una conversación mantenida con Díaz Grey. 5) El secreto, no obstante, nunca llega a descifrarse, al menos por parte de Jorge, ya que al final de todo el proceso de búsqueda vuelve al inicio, al único punto comprobable de la realidad, a la única escena supuestamente vista en persona por el médico (miembro solitario de su público): "Hubo una mujer que murió y la enterré. Y nada más. [...] todo es mentira" (2012: 184). Al denominar sus narraciones como mentira, vuelve a las premisas de verdadero-falso, inválidas dentro de la categoría de la ficción, por lo cual rechaza el hecho de que la invención de entornos y acontecimientos sin referencia exterior alguna pueda ser válida como una narración. 6) Pero de todas formas, es el secreto del arte de la narración el núcleo, el "lugar vacío" que une las diferentes sesiones de narración entre el joven y el médico, esto es, las múltiples historias que narra Jorge a lo largo del texto, logrando su concentración en un lugar, contando el mismo cuento de Rita y la cabra una y otra vez. Durante la primera cita Jorge pronuncia: "ni siquiera cuando hablábamos con Tito de la historia pude sentirla como una cosa completa, con su orden engañoso pero implacable, como algo con principio y fin, como algo verdadero, en suma. Tal vez ocurra ahora, cuando se la cuente, si encuentro la manera exacta de hacerlo", a lo que el médico responde simplemente "[p]ruebe" (2012, 130), formándose entre ellos un pacto secreto, y siendo por ello cada visita al médico uno de estos intentos de encontrar cómo contar.

De esta manera, Para una tumba sin nombre oculta un relato (el del Jorge pretendiente a escritor) dentro de otro relato (la historia de la cabra), de las que en ambas se pueden reconocer en grandes líneas los rasgos básicos de la propuesta de Ricardo Piglia sobre la definición de la nouvelle, habiendo probado así su vigencia en dos niveles diferentes de la misma narración. Si añadimos a ello el caso de Los adioses, texto objeto de la argumentación pigliana, y el hecho de que, tal como ya hemos citado, según Josefina Ludmer, la obra aquí analizada "exhibe al desnudo el molde de la narración que sostiene la mayoría de los relatos de Onetti" (1. La llegada de lo insólito 2. La investigación, normalmente con un narrador y dos informantes 3. El cierre, que normalmente significa el fracaso de la investigación o un resultado ambiguo) (2009: 178-184), lo cual conecta en varios puntos con las tesis piglianas, podríamos deducir que lo propuesto por Piglia se ajusta a un modelo al que Juan Carlos Onetti recurre con frecuencia en sus novelas breves.

En Para una tumba sin nombre, Onetti escribe dos novelas breves en una. La segunda requiere de la primera, por tener algún material en el que practicar el arte de narrar, pero no le es indispensable contar justo con esta historia de la cabra. El categórico "[ $\mathrm{t}]$ enemos al chivo y 
deduzco que es lo más importante" (Onetti, 2012: 146) pronunciado por el médico sería nomás un intento de desviar la atención, o puede ser realmente una indicación no hacia el lector, sino hacia Jorge, en cuya narración es, efectivamente, la figura de la cabra el punto de partida real en torno al que debería construir su ficción. Los elementos ambiguos de la primera historia - la inactividad del médico por comenzar el trabajo de investigación, su pronunciada indiferencia frente a los hechos de la realidad, su rechazo de toda prueba racional, o su trabajo de construir su versión de la nada- pueden verse como señales que indican la necesidad de mirar más allá de la primera lectura, elementos para despertar la duda del lector.

Y siguiendo esta llamada a mirar más allá, quiero opinar que la interrelación entre las dos caras de la estructura llega a superar la de la mera duplicación. Hasta ahora supusimos un plano real —el entierro que Díaz Grey dice haber visto, las conversaciones con Jorge y Tito, y el escenario desde donde se narra el nivel de la cabra - y uno ficcional - las narraciones sobre la prehistoria de Rita y la cabra-, lo cual, teniendo en cuenta el tipo de narrador principal con el que tenemos que ver aquí, se puede socavar fácilmente. En la narrativa de Onetti, Díaz Grey siempre ha tenido el rol del gran fabulador: desde que al final de La vida breve ha tomado la posición narradora de Brausen, es él quien rige los mundos de varias narraciones onettianas; aquí también, lo vemos crear de la nada la historia de Ambrosio, narrándola de manera tan fiable, que su pertenencia a la ficción queda casi desapercibida. ¿Por qué no sería posible, entonces, que todo lo percibido como real hasta ahora, sea también, nomás fabulación del narrador principal, narrando desde detrás de su escritorio? Él mismo confiesa al final de la obra: "Y cuando pasaron bastantes días de reflexión como para que yo dudara también de la existencia del chivo, escribí, en pocas noches, esta historia" (2012: 186), donde "esta historia" debe referirse a la totalidad de lo que hemos leído en las páginas anteriores. Y si ambos niveles son parte de la ficción, teniendo, por una parte, la ficción contada por Jorge y, por otra, la contada por Díaz Grey, el paralelismo entre la composición de estos dos hilos ya supera una mera duplicación de la estructura y lleva a una suerte de multiplicación hacia el infinito en el que los dos narradores son prisioneros el uno del otro: Jorge necesita de Díaz Grey para poder narrar (el médico es su narratario y también el que lo narra), pero al mismo tiempo, Díaz Grey también necesita de Jorge, siendo el camino como narrador y la narración de este último lo que compone el núcleo de la narración principal. Los dos narradores, entonces, están narrando mutuamente la historia del otro (el médico narra lo que narra Jorge, pero Jorge narra lo que luego narrará el médico), enfrentados los dos como espejos que se reflejan infinitamente. O poniendo el ciclo infinito de otra manera, Díaz Grey quiere reflexionar sobre el misterio de la cabra, y para ello recurre a la narración; y Jorge desea comprender el misterio de narrar, y para ello recurre a la historia de la cabra.

Paréntesis interpretativo aparte, a pesar de que el modelo pigliano sobre la nouvelle ha resultado aplicable sobre esta novela breve de Juan Carlos Onetti, añadiendo una más a la lista de títulos que refuerzan su vigencia, no nos podemos olvidar de que Ludmer, al formular la estructura onettiana antes mencionada que en tanto coincide con las tesis de Piglia, no habla específicamente sobre las novelas breves del uruguayo, sino sobre sus relatos en general. La estructura que aquí observamos está tan presente en sus cuentos (véase, por ejemplo, "Un sueño realizado"), como en alguna de sus novelas, como La vida breve. Por esta falta de exclusividad, preferiría tomar las tesis de Piglia no tanto como un modelo a seguir o un 
procedimiento infalible para trazar la línea divisoria entre cuento y novela breve, sino más bien como una posible estructura para la nouvelle, utilizada con preferencia por Onetti. Las sugerencias de Piglia son de gran utilidad en el trabajo de comprensión de las estructuras del uruguayo, y su aplicación durante el análisis puede ayudar a profundizar en la interpretación de la obra; pero no creo que definan el género. Las propuestas piglianas quedarían, entonces, como unas tesis sobre un posible modelo para armar una novela corta. De todas maneras, no será esta la última aproximación a la cuestión.

\section{Bibliografía}

\section{Obras citadas}

BENEDETTI, Mario (1968): "Tres géneros narrativos". En su libro Sobre arte y oficios. Editorial Alfa. Recuperado de: http://www.lanovelacorta.com/1872-1922/tgnmb.php [21/11/2018].

FERRO, Roberto (2011): Onetti / La fundación imaginada. La parodia del autor en la saga de Santa María. Buenos Aires, Corregidor.

LUDMER, Josefina (2009): “Contar el cuento". En su libro Los procesos de construcción del relato. Buenos Aires, Eterna Cadencia Editorial: 155-200.

ONETTI, Juan Carlos (2012): "Para una tumba sin nombre". Novelas breves. Buenos Aires, Eterna Cadencia Editora: 115-186.

PIGLIA, Ricardo (2006): "Secreto y narración. Tesis sobre la nouvelle". En Eduardo Becerra (ed.), El arquero inmóvil. Nuevas poéticas sobre el cuento. Madrid, Páginas de espuma: 187-205.

SAER, Juan José (2012): "Prólogo. Onetti y la novela breve". En Juan Carlos Onetti, Novelas breves. Buenos Aires, Eterna Cadencia Editora: 9-16.

\section{Obras mencionadas}

ONETTI, Juan Carlos (2007): La vida breve. Buenos Aires, Punto de Lectura.

--- (2012): Novelas breves. Buenos Aires, Eterna Cadencia Editora.

--- (2014): Cuentos completos. Madrid, Alfaguara.

PIGLIA, Ricardo (1999): "Nuevas tesis sobre el cuento". En su libro Formas breves. Buenos Aires, Temas Grupo Editorial: 102-134.

--- (2000): “Tesis sobre el cuento", Guaraguao 4:11 (2000): 17-19. Recuperado de: https://www.jstor.org/stable/25596169?seq=1\#metadata_info_tab_contents [21/11/2018].

(C) Gabriella Zombory

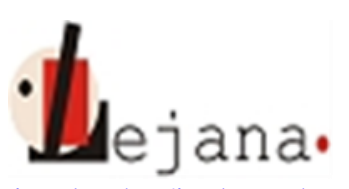

http://ojs.elte.hu/index.php/lejana

Universidad Eötvös Loránd, Departamento de Español, 1088 Budapest, Múzeum krt. 4/C 